\title{
Como Elstir pintaba el mar... La interpretación filosófica de la Recherche por Vincent Descombes*
}

\section{As Elstir Painted the Sea... The Philosophical Interpretation of the Recherche by Vincent Descombes}

\section{BlanCA FERNÁNDEZ GARCÍA}

Universidad de Bolonia

Via Cartoleira 5. Bolonia, 40124. Italia

blanca.fernandez@unibo.it

Orcid ID 0000-0001-9152-4296

Resumen: La interpretación filosófica de la $R e$ cherche realizada por Vincent Descombes rescata para la filosofía moral el potencial filosófico de la novela en sí. El énfasis puesto en la forma literaria novela como soporte de ese pensamiento útil a la filosofía moral resulta particularmente interesante: supone el reconocimiento del aspecto cognitivo presente en la tensión mimética de las formas literarias. En este artículo sugerimos la recuperación de una tradición específica de la poética en la que la realidad se contempla como uno de los elementos indispensables en el ejercicio de la creación literaria.

Palabras clave: Marcel Proust. Descombes. Interpretación. Filosofía moral. Mímesis.
Abstract: The philosophical interpretation of $\grave{A}$ la Recherche du temps perdu done by Vincent Descombes rescues the philosophical proposal of the novel itself for the moral philosophy. Its emphasis on the literary form 'novel' as a support of this thought useful to the moral philosophy is particularly interesting: it assumes the recognition of the cognitive aspect present on the mimetic tension of the literary forms. In this article we suggest recovering of a specific tradition of the Poetics where reality is shown as an indispensable part of the exercise of literary creation.

Keywords: Marcel Proust. Descombes. Interpretation. Moral Philosophy. Mimesis.

\footnotetext{
* Este trabajo se ha realizado en el marco del proyecto de investigación "Actualidad de la hermenéutica" (FFI2013-41662-P), financiado por el Ministerio de Economía y Competitividad para el periodo 2014-2018.
} 


\section{INTRODUCCIÓN}

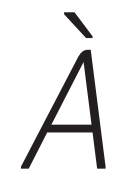

la Recherche du temps perdu ha sido considerada una novela clave para afrontar las relaciones entre filosofía y literatura. Es posible que tenga que ver con el hecho de que Proust, que dudaba si escribir un estudio de costumbres, un ensayo filosófico o una novela, terminara decantándose por esta última forma literaria pero sin llegar a desentenderse del todo de las otras posibilidades. También tiene seguramente mucho que ver con el hecho de que el narrador, permeado de filosofía clásica y contemporánea, no cesa de confundir y fluidificar los confines entre las dos prácticas. En efecto, sus reflexiones sobre el tiempo, el espacio, el sueño, la realidad, el olvido y la memoria, han sido a menudo percibidas por algunos filósofos como una instigación a ocuparse de la literatura (Simon 10-13).

La obra de Vincent Descombes, Proust: Philosophie du roman (1987), se incorpora a esta transitada senda que se interroga sobre las relaciones entre filosofía y literatura, ofreciendo como principal aportación una interpretación filosófica de La Recherche que se pretende asimismo una contribución a la filosofía moral. Movido por la consideración que Proust mismo tenía de su novela, ${ }^{1}$ Descombes aborda un análisis de la Recherche cuyas conclusiones extrapola finalmente al género novelesco en general, haciendo ver la utilidad de este en el ámbito de la filosofía moral.

Sin embargo, más allá de la extrañeza inicial que pudiera suscitar la idea de rescatar La Recherche, y la novela en general, como herramienta útil a la filosofía moral, la originalidad de Descombes radica, a mi entender, en que su interpretación se separa de las tendencias interpretativas que han tenido mayor peso en la lectura filosófica de La Recherche.

Nos referimos en primer lugar a la intuición de uno de los primeros lectores, el ya citado Rivière, que en 1913 anticipó que, en el tercer volumen, Le Temps retrouvé, el narrador daría una explicación filosófica de la novela, ya que los dos primeros volúmenes creaban un malentendido al presentarse como una suerte de reencuentro con los días vividos de la infancia y de la juventud (en 1913 la obra aún estaba estructurada en tres volúmenes). Algunos lectores, como por ejemplo Gilles Deleuze (Proust et les signes, 1964), han seguido este camino y han leído la novela a la luz del último volumen. En segundo lugar,

1. En una carta a Jacques Rivière, fechada el 7 de febrero de 1914, afirma que la suya es "una obra dogmática y una construcción" y que pretende una "búsqueda de la Verdad". 
las múltiples incursiones filosóficas del narrador han sido objeto de análisis privilegiado, en tanto que se presentan confundiendo, como decíamos, los límites entre literatura y filosofía. Por último, otra tendencia no incompatible con las anteriores ha sido la de entender la Recherche como una explicación novelesca del ensayo Contre Saint-Beuve, escrito entre 1908 y 1910.

Sin embargo, y a pesar de que efectivamente Proust abandonara el proyecto de ensayo (Contre Saint-Beuve) y tratara de retomar sus "dogmas" en Le Temps retrouvé, Descombes descarta una interpretación filosófica que consiste en "constatar el hecho de que una parte del texto sea ofrecida por Proust como comentario filosófico de la otra parte" (Descombes 14$){ }^{2}$ Distanciándose de estas interpretaciones, piensa que es más bien la novela misma la depositaria de un pensamiento filosófico. $\mathrm{Y}$ así, trata de demostrar que la parte especulativa de la Recherche -ya sea Le Temps retrouvé, ya sean las consideraciones filosóficas desperdigadas a lo largo de toda la novela- difícilmente puede ser considerada inteligible filosóficamente; ni siquiera una explicación filosófica de la novela.

En este sentido, la lectura de Descombes se distingue de otras aproximaciones filosóficas en que, reconociendo efectivamente que la Recherche es una construcción y una búsqueda de la verdad, busca esa verdad en su especificidad en tanto que texto literario y no en un ensayo dentro o fuera de la novela. Por ello resulta particularmente sugerente, ya que para extraer la filosofía de la Recherche, debe definirla en primer lugar como novela y diferenciarla del ensayo o de la literatura propiamente filosófica. Con este fin, y con la mira puesta en la utilidad de la Recherche para la filosofía moral, recorre algunas de las principales escuelas de teoría literaria del siglo Xx, entablando una fértil discusión que trata de romper el tabú textualista del texto como representación de la realidad.

El objetivo de este artículo será pues, no solamente la explicación de la interpretación filosófica de Descombes, sino también la sugerencia de la relación entre su interpretación de la novela y una parte de la tradición teóricoliteraria que considera la representación como asunto propio.

\section{Proust teórico y Proust novelista}

Como punto de partida para su reflexión, Descombes elige un personaje clave en la educación estética del narrador: Elstir, el pintor impresionista que Marcel conoce en Balbec. En la Recherche es el personaje que representa la pin-

2. La traducción de Descombes es siempre nuestra. 
tura, así como Vinteuil la música y Bergotte la literatura. Todos ellos son fundamentales en la formación de Marcel, ya que como artistas encarnan la dialéctica entre tradición y vanguardia. La figura de Elstir está inspirada en varios pintores impresionistas y su nombre es un acrónimo del pintor americano James Whistler. Marcel descubre un mundo nuevo en sus pinturas en las que se confunden el mar y el cielo, dibujados por la luz tal como estos se aparecen en algunos atardeceres de Balbec. Sin embargo, en el episodio al que nos remite Descombes el pintor impresionista emite un juicio impropio de un artista de vanguardia. En su valoración de la nueva iglesia de Marcouvillel'Orgueilleuse, Elstir adopta el poco afortunado criterio conservador del arqueólogo que prefiere las antiguas construcciones a las nuevas. Marcel, escandalizado, encuentra esta apreciación mucho menos interesante que el criterio estético que muestra en sus cuadros en tanto que "pintor-impresionista" y del que tanto ha aprendido. Elstir, al rechazar la iglesia porque es nueva, vendría a poner en cuestión las tesis que, según Marcel, como impresionista aplicaría en su propio trabajo:

¿No se contradice un poco con su propio impresionismo cuando excluye así los monumentos de la impresión global en que están comprendidos, los lleva fuera de la luz en que se funden y examina como arqueólogo su valor intrínseco? ¿Acaso cuando está pintando un hospital, una escuela, un letrero en una pared no tienen el mismo valor que una catedral inestimable que está al lado, en una imagen indivisible? (Proust 1987, 179)

Lo que le había llevado ya a concluir en Le Côté de Guermantes que:

De igual modo que en uno de los cuadros que había visto yo en Balbec, el hospital, tan hermoso bajo su cielo de lapislázuli como la misma catedral, parecía más audaz que Elstir teórico, que Elstir hombre de gusto y enamorado de la Edad Media, cantar: "No hay gótico, no hay obra maestra; el hospital sin estilo vale tanto como el glorioso pórtico/la gloriosa fachada". (Proust 1989, 481)

La reflexión que Proust presta al narrador a propósito de Elstir le sirve a Descombes para sostener, de manera análoga, una diferenciación fundamental para su interpretación: que también el Proust novelista es mucho más audaz (bardi) que el Proust teórico. Según esta idea, las interpretaciones filosóficas sobre la vida, el amor o el tiempo que han visto la transposición de la filosofía del autor en las reflexiones del narrador no estarían en condiciones de dar 
cuenta de la "audaz" filosofía de la Recherche que Proust, como artista, habría llegado a construir. Teniendo esto en cuenta, Descombes basa su análisis novelesco en la distinción entre un Proust "teórico" y un Proust "novelista".

¿En qué consiste pues la filosofía del Proust teórico expuesta por el narrador? En el capítulo titulado "El filósofo desconocido", Descombes ironiza sobre el narrador-doctor que pretende seleccionar para nosotros no solo lecciones sobre su vida, sino "grandes leyes" y "preciosas verdades" (Descombes 31). Para diferenciarlo del narrador, Descombes prefiere referirse a él como "pseudo Marcel": "Un filósofo francés que no ha dejado escritos y del que no sabemos nada de primera mano", empapado en "una doctrina que a finales del siglo pasado cualquiera hubiera podido profesar". La filosofía del pseudo Marcel, aunque no esté "escrita" ni sea reconocible en su logos, puede datarse fácilmente en el seno de la tradición francesa, ya que su programa filosófico revela el gusto de una época (Descombes 34-38). ${ }^{3}$

Según las digresiones especulativas mezcladas con la narración, este pseudo Marcel defiende en literatura las tesis de Contre Saint-Beuve: que la obra no se puede explicar por el autor; tesis sustentada a su vez en la filosofía de la subjetividad de las visiones del mundo, el solipsismo, la imposibilidad de comunicar, el idealismo de la representación, la teoría estética de las artes y el arte concebido como expresión de sí (Descombes 15-16).

Sin embargo, estas ideas que defiende el narrador como teorías estéticas que regirían la composición de la novela, son difícilmente compatibles con el ejercicio novelesco que pone en marcha el autor. La creencia de que no exista más que una lengua privada, la tentación solipsista, el mito de la interioridad, de la subjetividad de las visiones del mundo, etc., ¿pueden ser materia de novela?; y más en concreto ¿de esta novela en la que el narrador se lamenta de no poder abandonar lo que él llama el "salón mental" ni en los momentos en los que voluntariamente se aparta del mundo?

Para ilustrar este desfase, Descombes señala algunas contradicciones, como por ejemplo el personaje de Legrandin, presentado como un idealista subjetivo en sus declaraciones pero que en su "contingencia" novelesca es un arribista social (Descombes 16-17). Igualmente se refiere al problema del "cierre de las conciencias" ("clôture des conciences") que Proust teórico invoca sobre todo en momentos de celos o de fracaso amoroso: en estos momentos el na-

3. Anne Simon (15-22) ha incidido en la importante formación filosófica recibida por Proust. Ver también la reconstrucción de las fuentes filosóficas de Proust realizada por Luc Fraisse. 
rrador no es capaz de desentrañar qué es lo que pasa por la mente de Albertine. Sin embargo, en el resto de situaciones el narrador es absolutamente clarividente y el resto de los seres le resultan decididamente transparentes; y no solo al narrador: uno puede llegar a preguntarse hasta qué punto se le puede esconder algo a Françoise (Descombes 54).

Estas contradicciones demuestran que la filosofía idealista del "pseudo Marcel" no puede ser la filosofía de la novela. Descombes sostiene que el pensamiento "explícito" del Proust "teórico", expresado en las digresiones que se suceden a lo largo de la novela, no cumple los requisitos para que sea considerado una aclaración de orden filosófico porque ni es filosóficamente inteligible ni, como hemos visto, contiene el sentido del relato. Se trataría, como mucho, de filosofía en la novela, meros incisos de tinte especulativo. Sin embargo, Descombes no ceja en su búsqueda de una filosofía de la novela que se distinga de una filosofía en la novela.

Si esta última, como hemos visto, consiste en la transcripción explícita de los pensamientos del narrador, la filosofía de la novela habría sin embargo que ir a buscarla en la forma literaria misma.

\section{LAS LECCIONES DE ELSTIR Y LA FILOSOFÍA DE LA NOVELA}

El reconocimiento de una filosofía de la novela plantea el problema de determinar qué aspectos de este género literario pueden cifrar un pensamiento filosófico. Descombes intenta buscar en la propia estructura del género literario el equivalente a las proposiciones filosóficas.

Esta búsqueda parte de la convicción proustiana de la potencialidad del éclaircissement de la literatura. Según Proust escribir una novela exige un trabajo intelectual y moral cuyo objetivo es la aclaración de la vida -como explicaba en la carta a Jacques Rivière-. Y es precisamente en esta actividad en la que Descombes sostiene que podemos equiparar el novelista al filósofo: ambos cumplen el trabajo intelectual y moral de esclarecimiento que el filósofo realiza a través del examen de las proposiciones en las que se comunican estos pensamientos. Pero ¿cómo hace la literatura para esclarecer la vida a través de un relato novelesco? (Descombes 71).

En cualquier caso, la escritura de una novela puede comportar una etapa que podríamos llamar análisis novelesco (como se dice: análisis gramatical). Una idea cualquiera se convierte en "idea de novela" cuando el escritor ha encontrado el medio de "analizarla", es decir, de convertirla en un ar- 
gumento esquemático. [...] Podríamos decir que la filosofía de un autor de novelas hay que buscarla en la manera en que somete sus ideas (o las ideas de su tiempo) al análisis novelesco. (Descombes 90)

Por eso Legrandin no es la transposición del idealismo, ni un esclarecimiento sobre el idealismo a pesar de que se presente como un defensor del idealismo filosófico. Lo que el autor trata de hacer, es analizar a través de una "idea de novela", que sería el personaje Legrandin, un comportamiento social: el del personaje que se confiesa idealista, tratando al mismo tiempo de hacerse un lugar en el mundo de la alta sociedad. Esto no significa que se quiera tachar al idealista o al idealismo de ideología arribista; en la novela no existe ningún personaje que sea la verdad del idealismo, lo que tenemos es el personaje de Legrandin en el que hay que ver una "idea de novela" (Descombes 16-17). ${ }^{4}$

Las unidades argumentales que Descombes llama "ideas de novela", como el ejemplo recién citado, permiten a los escritores analizar distintos aspectos de la realidad, equiparándose en este empeño a los filósofos. Lo que nota Descombes en su obra de 1987 -abriendo una veta que otros filósofos como Bouveresse o Nussbaum van a explotar más adelante- es que en la novela en general, no solo en la de Proust, si bien en ella especialmente, hay una tendencia a analizar comportamientos humanos. En este sentido Descombes ve la contribución esclarecedora de la Recherche en que esas "ideas de novela" apuntan en su mayoría a la elucidación de comportamientos y sentimientos humanos.

En el caso concreto de la Recherche, el análisis novelesco de comportamientos humanos tendría mucho que ver con las enseñanzas que el narrador extrae de sus visitas al taller de Elstir. Marcel, a pesar de no tener ningún obstáculo en su carrera como escritor (es rico, su familia acepta la elección, nadie le exige que se case, etc.), está frustrado porque cuando observa el mundo a su alrededor -prosaico, aburrido, exento de belleza- no encuentra "ideas" o ins-

4. En este sentido la filosofía sufre también su análisis como "idea de novela". Como observa Descombes (31-33), Bergotte es un escéptico, Brichot un superficial, el único filósofo que aparece como tal es un noruego que habla despacio (porque acaba de aprender el francés y no tiene soltura y porque es un metafísico, lo que ralentizaría la conversación también para un francés) y Mme. Verdurin interrumpe su discurso, del mismo modo que Mme. de Guermantes interrumpe la recitación poética de Rachel. Como la poesía, en tanto "idea de novela", la filosofía no ocupa más que un lugar conflictivo y escaso en la Recherche. La novela puede contar la historia del escritor que viene de provincias pero no la historia del escritor o del artista haciendo su obra o escribiendo. Bergotte mismo no aparece sino como hombre de mundo y de su trabajo como escritor nos quedan algunos retazos, fragmentos de frases únicamente. 
piración para escribir. La belleza parece restringida a los paisajes de Combray o de Balbec donde evita la presencia de sus congéneres. Sin embargo, a nivel literario se revelan bastante poco fértiles, dando lugar como máximo a ejercicios escolares y poemas en prosa. El narrador, al adoptar la postura del esteta, parece caer en el mismo error que Elstir teórico o arqueólogo que desprecia la iglesia nueva de Marcouville-L'Orgueilleuse. Sin embargo, gracias a Elstir pintor impresionista comprenderá que no solo lo que aparece bello, alto o noble, es materia literaria.

La lección aprendida de Elstir pintor-impresionista, que dignifica en sus cuadros el hospital o la escuela colocándolos a la misma altura artística que la catedral, permitirá al narrador utilizar en su novela personajes de su mundo, vulgares como los Verdurin o Brichot (y en general, a pesar de las apariencias, toda la sociedad que frecuenta), que no se corresponderían con la imagen de lo "novelesco" que da a entender el autor. Esta estaría ligada más bien a las fantasías caballerescas, al roman courtois, o a las ensoñaciones ociosas del narrador aburrido de la realidad y deseoso de vivir como en una de esas novelas. Dentro de su construcción novelesca, los Verdurin, Legrandin, etc. representarán, según Descombes, "ideas de novela". Todos estos episodios y personajes no responden ya al gusto o a las preferencias estéticas del narrador, sino a la nueva construcción de Proust, a su novela.

$\mathrm{Al}$ vencer sus reservas de regusto clásico, Descombes observa que el narrador convoca una serie de "ideas de novela" que tienen que ver más con las relaciones sociales que con las especulaciones filosóficas en las que esporádicamente se adentra el narrador. Lo que el escritor logra a través de su trabajo intelectual y moral es la descripción de las relaciones humanas. Esquematiza en argumentos un mundo y el modo de interacción entre los individuos que pertenecen a él. Es por ello que Descombes ve en Proust un grandísimo potencial filosófico como sociólogo:

Como se verá, yo espero de una lectura filosófica una aclaración de nuestro vocabulario para la descripción de los asuntos humanos. La Recherche aparenta ser un libro filosófico que trata dogmáticamente del Tiempo y de la Esencia. Pero la Recherche es un libro filosóficamente instructivo por los conceptos que el novelista "pone en práctica" al pensar "como novelista" (en romancier), para construir su historia. Cito desordenadamente: el prestigio, el malentendido, la distinción, la elección y la exclusión, el encanto personal, el desdén, los deberes y obligaciones, el aburrimiento y la exaltación, la conversación, el estar en la casa propia (chez soi), el va- 
lor mundano, el arte de las distancias, etc. todo esto compone la filosofía proustiana de la novela, [...] superior a la filosofía proustiana del ensayo. (Descombes 19)

La principal contribución filosófica de la novela radicaría para Descombes en la riqueza de vocabulario útil para describir las acciones humanas. Conclusión que extiende a todo el género novelesco, donde observa una mayor inclinación al análisis de los seres humanos y de su relación con el mundo (Descombes 19). La aportación filosófica de la Recherche podría recaer por tanto, como sugiere Descombes, en el ámbito de la filosofía moral; en concreto en lo que Aristóteles llamó en la Ética a Nicómaco, "la filosofía de los asuntos humanos" [he peri ta anthropina philosophia] (1181b15):

La cuestión es que la filosofía moral, en nuestra época reducida a una cuestión de ética individual, reduce sus reflexiones al fundamento de la evaluación moral, es decir, en nombre de qué juzgar, y no cómo juzgar, es decir: en qué términos, sirviéndose de qué vocabulario, puesto que en esto, como en el resto de cuestiones, el pensamiento filosófico se queda en lo superficial si no es precedido de una descripción de fenómenos. Los "fenómenos", en el orden de los asuntos humanos, son las cosas que decimos, las formas comunes de pensar y de juzgar. [...] Los filósofos tienen una gran necesidad de leer novelas si es cierto que la forma novelesca es hoy la más rica en legomena, en muestras de las maneras comunes de pensar que son la materia prima de la filosofía práctica. (Descombes 17-18)

Esta sería la contribución principal de la Recherche a la filosofía que se extrae de la interpretación de Descombes en 1987. Se trata de una lectura social de la Recherche que ya había sido practicada por Adorno, Benjamin o Girard, y que en los últimos años parece estar ganando adeptos como muestran los trabajos más recientes de Jacques Bouveresse o Martha Nussbaum, que se orientan sobre todo a una lectura moral de las novelas y particularmente de la novela de Proust. ${ }^{5}$ Estas nuevas propuestas interpretativas buscan "descifrar las implicaciones morales" en la novelas contemporáneas, aspecto descuidado por

5. En este sentido Jacques Bouveresse o Martha Nussbaum han visto, como Descombes, la aportación de la novela a la filosofía moral. Otros autores como Jacques Rancière, más orientado a lecturas sociales, ha señalado la interacción de las formas con la política (entendida esta en un sentido amplio). Pierre Macherey (y también Bouveresse) ha analizado cómo se produce la búsqueda de la Verdad en la Recherche. 
las corrientes teóricas de raigambre estructuralista que no habrían sido capaces de dar cuenta del pulso que en este ámbito habían planteado novelistas como Zola, Dickens, James, Proust o Musil, por citar algunos (Bouveresse 12). Estos filósofos compartirían el diagnóstico realizado por Descombes a finales de los años ochenta y proponen a los filósofos prácticos que retomen, en el marco vivencial y cognitivo que las formas novelescas nos ofrecen, la vieja pregunta de la filosofía sobre cómo habría que vivir la vida (Nussbaum 23).

\section{TEORÍA LITERARIA Y FILOSOFÍA MORAL: ULISES Y SUS CIRCUNSTANCIAS}

Si, según Descombes, la Recherche supondría una interesante contribución a la filosofía moral, como hemos visto, su interpretación ofrecería también algunas reflexiones de interés para los teóricos de la literatura, pues es precisamente el énfasis en la cuestión novelesca lo que permite a Descombes extraer la utilidad filosófica de la novela. ${ }^{6}$ Pero para hacerlo necesita un análisis previo de la forma novelesca, lo que le obligará a plantearse cuestiones de poética o de teoría literaria.

La extensión a la filosofía moral de la novela en tanto que género, se apoya en la relevancia del "mundo" en ella. Sin embargo, la idea de dar paso al mundo moral en los textos literarios entraría en contradicción con una de las tendencias prevalentes en la teoría literaria en el siglo xx. Nos referimos a la cuestión de raigambre cientificista sobre la inmanencia textual. El formalismo, a principios del siglo, y sus desarrollos estructurales posteriores (en este caso concreto, la narratología) defendieron como garante de cientificidad en el estudio de la literatura la permanencia dentro de las fronteras textuales. De ahí que la potencialidad referencial de los textos se limite a la autorreferencialidad o al comercio intertextual siempre dentro del espacio literario, nunca a la realidad. Este veto extratextual fue adoptado y adaptado también por el posestructuralismo, que no solo negaba la posibilidad de salir del texto, sino que negaba también la misma existencia de una realidad fuera del texto.

$\mathrm{El}$ problema es que, como explica Bouveresse a lo largo de su libro $\mathrm{La}$ Connaissance de l'écrivain, el hecho de considerar a la literatura como únicamente autorreferencial no permitiría explicar gran parte de las novelas de los

6. Nussbaum también insistirá en la importancia de la forma como presupuesto: ver la introducción a Love's Knowledge, "Form and Content, Philosophy and Literature", donde sostiene que el estilo da su propia visión de lo que es importante. 
dos últimos siglos. A su entender, el estudio inmanente de los textos literarios no habría permitido afrontar las implicaciones morales o vitales de gran número de las novelas contemporáneas. En este punto Descombes mantiene una fértil discusión con el pensamiento estructuralista y posestructuralista que le proporcionará una base fundamental para defender su interpretación de la novela como fuente de la filosofía moral.

En la discusión con el posestructuralismo, cuyas tesis escépticas son ampliamente desgranadas y argüidas, denuncia lo metafísico de la pregunta misma por la literatura tal como la plantean -“¿qué es la literatura?”- y señala la imposibilidad de llegar, a partir de ahí, a otra respuesta que no sea la que efectivamente propone el posestructuralismo: la esencia de la literatura es el acto puro de la simple escritura. Lo que a su vez seguiría siendo una respuesta esencialista (muy a pesar de la crítica del posestructuralismo a la metafísica) y de la que sería imposible extraer una interpretación filosófica. Ante lo que considera un callejón sin salida, Descombes sugiere un desplazamiento hacia la cuestión genérica y atenerse a las formas novelescas. Ello le lleva a una fructífera discusión con la narratología.

Es particularmente interesante para el propósito de Descombes la discusión con la narratología que mantiene en el capítulo 9, titulado "Marcel devient écrivain". Precisamente la crítica a la narratología se sustenta en la atención que concede a la acción en detrimento de los contextos en los que se desenvuelve dicha acción. Lo que no tendrían en cuenta los narratólogos, cuando tratan de plantear una estructura común a todos los relatos y proponen una traducción sintáctica de su contenido, es el mundo en el que se desenvuelve la acción. Es decir, cuando reducen la Recherche a una oración como "Marcel se hace escritor" o la Odisea a "Ulises regresa a Ítaca" (ver Genette 75), prescinden justamente del contexto que determina los problemas de Ulises para regresar a casa o las dificultades de Marcel para convertirse en escritor. Descombes observa que de una oración como "Ulises regresa a Ítaca" no se podría hacer una traducción inversa y llegar a la Odisea.

Sin embargo, apela al logos de la Odisea transcrito por Aristóteles, en el que sí se da cuenta del ethos de la Odisea que, con sus fuerzas adversas y favorables, estaría en condiciones de definir de manera mucho más satisfactoria su contenido. ${ }^{7} \mathrm{Al}$ atender al mundo de la novela, tal como lo hace Aristóteles, ob-

7. Para una profundización en este aspecto, ver Pierre Vinclair. 
servamos que Proust ofrece una novela rica en descripciones de las relaciones humanas. Es capaz de poner en "ideas de novela" un conjunto de cuestiones relativas a la sociedad, que tienen sentido porque se desarrollan en un mundo concreto, en circunstancias particulares, que permiten comprender esos problemas.

Esta crítica a la narratología sería fundamental para la interpretación no solo de la Recherche, sino que se suma a interpretaciones de la literatura donde, teniendo en cuenta la especificidad de lo literario, se analizan los mundos que pueblan las novelas y el valor referencial de las mismas. La interpretación que hace Descombes atiende a lo literario como una elaboración artística de la vida.

\section{CONCLUSIÓN}

El hecho de haber realizado un esfuerzo analítico y filosófico sobre el género novelesco presupone el reconocimiento de un pensamiento inscrito en la forma novelesca equiparable al pensamiento filosófico. Efectivamente, según Descombes, filosofía y literatura (novela) compartirían la voluntad de esclarecimiento de la realidad: mientras que la filosofía lo hace a través de los conceptos, la novela lo haría a través de las "ideas novelescas". Esto significa que, en tanto construcción en la que se analizan aspectos de la realidad, Descombes otorga un valor de Verdad a la obra literaria y reconoce la necesidad de restablecer mediante la interpretación (filosófica) los vínculos entre la novela y el mundo que esta pretende esclarecer.

La referencialidad y el reconocimiento de un pensamiento inscrito en la forma novelesca lo acercan, dentro de la teoría literaria, más bien a una tradición teórico-literaria que va desde Aristóteles a Auerbach. Entre ellos media la larga reflexión sobre el estilo:

La teoría literaria es en efecto la teoría de los estilos, pero a condición de tomar la palabra estilo en el sentido clásico de una forma de presentación, como en la vieja teoría de los tres estilos que estudia Auerbach en Mimesis. El objeto de la teoría literaria es tratar sobre las diferentes formas literarias, de manera que permitan el planteamiento de problemas literarios. Ahora bien, el problema literario, según Proust novelista, es en suma el siguiente: ¿qué estilo se debe adoptar para presentar las cosas en cada caso concreto? (Descombes 233) 
Descombes, al retomar el problema de la interacción de las formas, se muestra deudor de esta corriente clásica de la poética que reconoce la especificidad de lo literario en la tensión mimética. Evidentemente, como aprendió Marcel de Elstir y como Auerbach observó ya en la escritura de los Evangelios, no se trata de aplicar una jerarquía de formas y contenidos, sino de reconocer que en toda escritura hay una tensión representativa de donde, por otra parte, emanaría su fuerza literaria. El esfuerzo intelectual y moral del escritor del que habla Proust -y que Descombes denominará la puesta en "ideas de novela"consiste en elegir un modo de presentación de los hechos que facilite una experiencia cognitiva.

El aprendizaje de Marcel, puesto en "idea de novela", explica muy bien esta tensión. Cuando Elstir pinta el mar siguiendo sus impresiones visuales y no lo que sabe de él, da una lección sobre el modo de presentación de las cosas, sobre los prejuicios que pesan en la representación mental de las mismas y sobre la potencialidad cognitiva de liberarse de ellos. Lección que el narrador expondrá en la célebre conversación con Gilberte en Le Temps retrouvé: habría que contar una guerra o un amor como Elstir pintaba el mar, no de manera pretendidamente científica, sino a través de las impresiones sensibles, igual que Dostoievski presentaba la vida en sus novelas e igual que Proust querrá contarnos la vida pasada no a partir de los recuerdos, sino a partir de las cosas tal como estas han sido olvidadas. ${ }^{8}$ Es ahí donde habría que buscar esa tensión mimética de La Recherche y la madurez de Marcel, que finalmente se hace escritor.

La interpretación de textos literarios tendrá que tener en cuenta el reconocimiento de la presencia en la literatura, y de modo particular en la novela, de una tensión mimética con el mundo cargada de potencial cognitivo. Parece que la tendencia apunta a aceptar que "entre los valores literarios, más allá de que la literatura hable de sí misma, considerarían el hecho de que la literatura habla también de la verdad, de la vida del ser humano o de la ética" (Bouveresse 12). Lo que no está reñido, como hemos visto en Descombes, con la consideración de la literatura como discurso con formas y procederes propios; al contrario.

8. Este argumento es tratado y discutido en profundidad también por Descombes en el capítulo "Le côté Dostoievski de Mme de Sévigné" como parte de la filosofía de la novela. Ver también el análisis del potencial cognitivo de este modo de presentación pictórica y literaria en Ginzburg. Otro autor que hará suyo este principio cognitivo de "contar la vida como esta ha sido olvidada" es Walter Benjamin en su proyecto sobre los pasajes de París. 


\section{OBRAS CITADAS}

Bouveresse, Jacques. La Connaissance de l'écrivain: Sur la littérature, la vérité et la vie. Marseille: Agone, 2008.

Descombes, Vincent. Proust: Philosophie du roman. Paris: Minuit, 1987.

Fraisse, Luc. L'Eclectisme philosophique de Marcel Proust. Paris: Presses de l'Université Paris-Sorbonne, 2013.

Genette, Gérard. Figures III. Paris: Seuil, 1972.

Ginzburg, Carlo. "Extrañamiento: prehistoria de un procedimiento literario". Ojazos de madera: nueve reflexiones sobre la distancia. Madrid: Península, 2000.

Nussbaum, Martha. Love's Knowledge: Essays on Philosophy and Literature. Oxford/New York: Oxford UP, 1990.

Proust, Marcel. En busca del tiempo perdido, III: El mundo de Guermantes. Madrid: Alianza, 1989.

Proust, Marcel. En busca del tiempo perdido, v: La prisionera. Madrid: Alianza, 1987.

Simon, Anne. Proust e la filosofia contemporanea. Chieti: Solfanelli, 2013.

Vinclair, Pierre. "Éléments pour une noétique du roman". Methodos 15 (2015). 18 de abril de 2017. <http://journals.openedition.org/methodos/4194>. 